\title{
EFFECTS OF SUPERCRITICAL CARBON DIOXIDE PROCESSING ON THE PROPERTIES OF CHITOSAN-ALGINATEMEMBRANES
}

\author{
Cecilia Zorzi Bueno ${ }^{\mathrm{a}}$, Ângela Maria Moraes ${ }^{\mathrm{a}^{*}}$, Hermínio C. de Sousa $^{\mathrm{b}}$, \\ Mara Elga MedeirosBraga ${ }^{b^{*}}$ \\ ${ }^{\text {a }}$ Department of Engineering of Materials and of Bioprocesses, School of Chemical Engineering, \\ University of Campinas, 13083-852 Campinas, SP, Brazil \\ ${ }^{\mathrm{b}}$ CIEPQPF, Department of Chemical Engineering, Faculty of Sciences and Technology, \\ University of Coimbra, 3030-790 Coimbra, Portugal. \\ Corresponding authors: e-mail:ammoraes@feq.unicamp.br, Telephone: (+55) 1935213920 ; \\ e-mail: marabraga@eq.uc.pt, Telephone (+351) 239798758
}

\begin{abstract}
Chitosan-alginate membraneswith different porosities designed to be used as wound dressings or scaffolds were processed in supercritical $\mathrm{CO}_{2}\left(\mathrm{scCO}_{2}\right)$ with the aim of improving their physicochemical properties. The membranes were characterized before and after processing at 100 or 300 barand $45^{\circ} \mathrm{C}$ for 2 hours with a depressurization rate of $5 \mathrm{bar} / \mathrm{min}$. The results show that after processing, thickness, real density and porosity increased up to $68 \%, 100 \%$ and $167 \%$, respectively, and surface area decreased up to $47 \%$. Because of changes in structure, water vapor sorption and permeability increased up to $53 \%$ and $84 \%$, respectively. Stabilization of the chitosan-alginate complex was noticed after processing with $\mathrm{scCO}_{2}$ according to thermal analysis. The results indicate that supercritical $\mathrm{CO}_{2}$ processingmade the membranes more adequate for use as wound dressings.
\end{abstract}

Keywords: Chitosan-alginate membranes, biopolymers, supercritical $\mathrm{CO}_{2}$ processing, biomedical applications

\section{Introduction}

Chitosan and alginate are among the polysaccharides most frequently studied for biomedicalapplications[1]. Chitosan is a linear polysaccharide, composed of units of 
glucosamine and $\mathrm{N}$-acetyl glucosamine. Itobtained by deacetylation of chitin, a polysaccharide found in the exoskeleton of crustaceans, insects and also in fungi. Chitosan isrecognized by its unique properties, such as non-toxicity, biocompatibility and biodegradability [2].Alginate is a linear polysaccharide consisting of alternating blocks of $(1,4) \beta$-D-mannuronate $(\mathrm{M})$ and $\alpha$-L-guluronate $(\mathrm{G})$. For commercial purposes, it is extracted from brown seaweeds [2].Alginate can absorbwater/body fluids up to 20 times its weight providing a moist wound-healing environment [3].

The formation of chitosan-alginatepolyelectrolyte complex(PEC) is a result of strong electrostatic interactions between amino groups of chitosan and carboxyl groups of alginate. Compared with alginate or chitosan gels alone, the PEC possesses many improved physicochemical properties such as higher stability to $\mathrm{pH}$ changes and improved effectiveness as controlled-release systems[1,2]. This PEC can be used in many advanced biomedical applications, such as wound dressings, drug delivery and tissue engineering [2].

In previous works[4,5], the development and characterization of porous chitosanalginate PEC membranes obtained through the addition of a non-ionic surfactant Pluronic F68compatible with the human skin [6] was described. Pore formation upon the addition of Pluronic F68 to the PEC occurred due to its high hydrophilicity and capacity of forming foams in aqueous solutions under stirring. Bueno et al. [5] found that the higher the amount of surfactant added, the higher the air retention in the polymeric mixture and, consequently, the higher the pore size of the dried biomaterial. These membranes, produced through a simple and low-cost method, were considered as potential candidates for wound dressings and for the use in tissue engineering as skin scaffolds. 
Supercritical $\mathrm{CO}_{2} \quad\left(\mathrm{scCO}_{2}\right)$ technology may be employed as a polymer plasticizing/swellingstrategy, with the capability of changing the porosity and consequently the permeability of the material to gases and moisture.Polymer matrices incorporating bioactive agents may be additionally modified regardingthe kinetic behavior release of the compound. Changing process conditions such as $\mathrm{CO}_{2}$ pressure, residence time and depressurization rate may then be used to attain desired properties of porosity, permeability and release kinetics [7-9].

Only a few works about $\mathrm{CO}_{2}$ processing of biopolymers are available in the literature, what can be probably attributed to the heterogeneity of the natural matrices which limits the study of processing effects [7-9].In addition, natural polymers such as cellulose, chitin, gelatin, and chitosan present some crystallinity and show little or no absorption of $\mathrm{CO}_{2}$ in the solid state. However, and since chitosan-alginate polyelectrolyte complexes (PEC) are more stable, processing effects may be more effective in this type of matrix. Considering the benefits about using $\mathrm{scCO}_{2}$ technology to process polymer matrices, and the lack of data regarding the use of this strategy, $\mathrm{CO}_{2}$ processing of chitosan-alginate PEC membranes could be a novel approach to modify, control, and even improve the biomaterial properties.

Therefore, the main purpose of this work was to determine the effects of this process on the physicochemical properties of membranes having different porosities.

\section{Materials and Methods}

2.1 Materials - Chitosan-alginate membranes were prepared using chitosan from shrimp shells, having a deacetylation degree of $95 \pm 1 \%$ asdetermined by a titrimetric method, and low viscosity sodium alginate, both from Sigma-Aldrich (United States). The molar masses of the polymers were determined by viscosimetry (capilarviscosimeterOstwald- 
Cannon-Fenske, n.200), being equal to $1.26 \times 10^{6} \mathrm{~g} / \mathrm{mol}$ for chitosan and $4.69 \times 10^{4} \mathrm{~g} / \mathrm{mol}$ for alginate.

Pluronic F68, currently available as Poloxamer 188, was obtained from Sigma-Aldrich (United States), calcium chloride dihydrate and sodium hydroxide were obtained from Merck (Germany), acetic acid was obtained from Synth (Brazil) and $\mathrm{CO}_{2}$ at $99.998 \%$ was obtained from Praxair (Spain).

\subsection{Preparation of the membranes}

Chitosan-alginate $(1: 1)$ porous membranes were prepared in the presence of Pluronic F68 at $2 \%$ and $10 \%(\mathrm{w} / \mathrm{w})$ in relation to the total polysaccharides mass.For the preparation of the membranes, $90 \mathrm{~mL}$ of $1 \%(\mathrm{w} / \mathrm{v})$ chitosan in $2 \%(\mathrm{v} / \mathrm{v})$ aqueous acetic acid were added to $180 \mathrm{~mL}$ of $0.5 \%(\mathrm{w} / \mathrm{v})$ alginate containing or not Pluronic F68 at $2 \%$ or $10 \%(\mathrm{w} / \mathrm{v})$ at $200 \mathrm{~mL} / \mathrm{h}$, with the aid of a peristaltic pump (model Minipuls 3, Gilson). The reaction occurred in a jacketed stainless steel tank with internal diameter of $10 \mathrm{~cm}$ and height of 20 cmat a stirring rate equal to $500 \mathrm{rpm}$ (mechanical stirrer model Q251D, Quimis, with a $4 \mathrm{~cm}$ in diameter three tilted-blade propeller), at $25^{\circ} \mathrm{C}$ (temperaturemaintained with a thermosthatic bath Q-214M2, Quimis). The final suspension was homogenized at $1000 \mathrm{rpm}$ for 10 minutes. Afterwards, $1 \mathrm{M} \mathrm{NaOH}$ was added to increase the $\mathrm{pH}$ to 5.3, under the same stirring rate, for 10 minutes. Then, $3.6 \mathrm{~mL}$ of $2 \%(\mathrm{w} / \mathrm{v}) \mathrm{CaCl}_{2}$ aqueous solution were added to crosslink the alginate carboxyl groups that were not bounded to the chitosan amino groups and the suspension was stirred for 10 minutes more. The amount of $\mathrm{CaCl}_{2}$ added was previously establishedby Rodrigues [10] aiming to ensure carboxyl groups crosslinking while avoiding excess gelification and consequent PEC precipitation. The membranes were prepared by casting: the polymeric mixture was transferredin equal mass proportions to 
two polystyrene Petri dishes having diameters of $15 \mathrm{~cm}$, then the material was dried in an oven with air circulation (model $410 \mathrm{D}$, Nova Ética) at $60^{\circ} \mathrm{Cuntil}$ achieving constant weight. The membranes were removed from the Petri dishes and immersed for 30 minutes in $150 \mathrm{~mL}$ of $2 \%(\mathrm{w} / \mathrm{v}) \mathrm{CaCl}_{2}$ for further crosslinking. The second crosslinking step is crucial because, if the membranes are directly exposed to water after the oven-drying step, the free alginate chains dissolve, resulting in a heterogeneous membrane [10].The membranes were then washed twice for 30 minutes in $200 \mathrm{~mL}$ of deionized water to remove theresidual acetic acid not eliminated during the casting process, deemed toxic to the selected applications, and dried at $37^{\circ} \mathrm{C}$ for 6 hours, with their borders attached to the Petri dishes to avoid shrinking. Samples were designed as P0\%, P2\% and P10\% according to their Pluronic F68 content.

\subsection{Supercritical $\mathrm{CO}_{2}$ processing}

The employed supercritical apparatus was already described in literature [7]. The system was comprised of a high pressure liquid $\mathrm{CO}_{2}$ pump, a stainless steel high pressure cell with approximately $10 \mathrm{~cm}^{3}$ of internal volume, a temperature-controlled water bath (Haake DC30, Thermo Electron Corporation) and a pressure transducer (Datum $2000^{\mathrm{TM}}$, Setra).

The cell, containing $1 \mathrm{~cm} \times 1 \mathrm{~cm}$ membrane samples in stainless steel supports (as shown in Figure 1), was pressurized at 100 or 300 bar at $45^{\circ} \mathrm{C}$ for 2 hours. At the end of the process, depressurization of the system was carried at $5 \mathrm{bar} / \mathrm{min}$. Different pressures were employed since this operational condition strongly influences both $\mathrm{scCO}_{2}$ density and solubilizing capacity, which could assist on the definition of future conditions for the impregnation of bioactive compounds in the membranes.Before being exposed to $\mathrm{CO}_{2}$, the samples (P0\%, $\mathrm{P} 2 \%$ and $\mathrm{P} 10 \%$ ) were kept at $20 \%$ relative humidity for 
48 hours before processing.

\subsection{Physical and chemical characterization}

Since the obtained membranes are hygroscopic and may dry in excess at very low relative humidity, turning too brittle, the samples were kept at $20 \% \mathrm{RH}$ for 48 hours before most of the characterization tests, namely, thickness, surface area, real density, porosity, water vapor sorption, water contact angle and simultaneous data thermal analysis (SDT). This condition was deemed as adequate for storing the samples for commercialization purposes. Before the scanning electron microscopy (SEM) analysis, it was necessary to keep the samples in a desiccator with silica gel for 48 hours, since water may interfere negatively in the results. Finally, before water vapor permeability tests, the samples were previously kept at 50\% RH for 48 hours according toRhim [11] and Moraesand Beppu [12], aiming at simulating the conditions of use on the lesioned skin as dressings.

\subsubsection{Aspect}

The aspect of the membranes was inspected visually regarding color change and material integrity.

\subsubsection{Morphology}

Detailed analysis of the membranes morphology was performed by scanning electron microscopy (SEM) with a microscope (model LEO 440, Leica) at $10 \mathrm{kV}$ and 50pA. The samples were previously coated with an ultra-thin layer of gold $(92 \AA)$ in a mini Sputter coater (SC 7620, VG Microtech). 


\subsubsection{Thickness}

The thickness of samples was measured with a digital micrometer(model MDC-25S, Mitutoyo), being reported as the average of 10 individual measurements.

\subsubsection{Surface area, real density and porosity}

The surface area of the membranes was measured by $\mathrm{N}_{2}$ adsorption(Micrometrics ASAP 2000 V2.04.), and calculated with the BET equation (Equation 1):

$$
\frac{1}{\left[V_{a}\left(\frac{P_{0}}{P}-1\right)\right]}=\frac{C-1}{V_{m} C} \times \frac{P}{P_{0}}+\frac{1}{V_{m} C}
$$

where $\mathrm{P}(\mathrm{Pa})$ is the partial vapor pressure of $\mathrm{N}_{2}$ gas in equilibrium with the surface at 77.4 $\mathrm{K}$ (boiling point of liquid $\left.\mathrm{N}_{2}\right), \mathrm{P}_{0}(\mathrm{~Pa})$ is the saturated pressure of $\mathrm{N}_{2}, \mathrm{~V}_{\mathrm{a}}(\mathrm{mL})$ is the volume of gas adsorbed at standard temperature and pressure $\left(273.15 \mathrm{~K}\right.$ and $1.013 \times 10^{5}$ $\mathrm{Pa}), \mathrm{V}_{\mathrm{m}}(\mathrm{mL})$ is the volume of gas adsorbed at standard temperature and pressure to produce an apparent monolayer on the sample surface, $\mathrm{C}$ is a dimensionless constant that is related to the enthalpy of adsorption of the adsorbate gas on the powder sample. After plotting $1 /\left[V_{a}\left(P_{0} / P-1\right)\right]$ against $P / P_{0}, V_{\mathrm{m}}$ is calculated by linear regression and the specific surface area is calculated according to Equation 2:

$$
S=\frac{V_{m} N a}{m \times 22400}
$$

where $\mathrm{N}\left(\mathrm{mol}^{-1}\right)$ is the Avogadro constant, a $\left(\mathrm{m}^{2}\right)$ is the effective cross-sectional area of one $\mathrm{N}_{2}$ molecule and $\mathrm{m}(\mathrm{g})$ is the mass of the sample.

The real density was measured by helium pycnometry(Accupyc 1330Micrometrics, USA).

The total porosity was calculated according toEquation3:

$$
P_{t}=1-\rho_{\text {apparent }} / \rho_{\text {solid }}
$$


where $\rho_{\text {apparent }}\left(\mathrm{g} / \mathrm{cm}^{3}\right)$ is the apparent density (calculated as the ratiobetween the mass and the volume of each sample), and $\rho_{\text {solid }}\left(\mathrm{g} / \mathrm{cm}^{3}\right)$ is the real density measured by helium pycnometry.

\subsubsection{Water vapor sorption}

Water vapor sorption was evaluated gravimetrically, according to Dias et al. [8], by measuring the gradual increase inweight of $1 \mathrm{~cm} \times 1 \mathrm{~cm}$ samples (in95\% RH at $32^{\circ} \mathrm{C}$ ). The experiments were performed in triplicate. Vapor sorption capacity was calculated according to Equation 4, in which $W_{t}$ is the weight of the sample at time $t$ and $W_{0}$ is the initial weight of the sample.

$V_{s}=\frac{\left(W_{t}-W_{0}\right)}{W_{0}} \times 100$

(Equation4)

\subsubsection{Water vapor permeability}

Water vapor permeability was evaluated by a gravimetric method adapted from ASTM E96-95 [13]. The experiments were performed in triplicatewith $1.2 \mathrm{~cm} \mathrm{x} 1.2 \mathrm{~cm}$ samples, which were fixed at the top of small flasks containing silica gel, resulting in an available area for contact with air equal to $0.6362 \mathrm{~cm}^{2}$. The flasks were stored at $50 \%$ $\mathrm{RH}$ at $32^{\circ} \mathrm{Cand}$ had their weights measured periodically during 24 hours. Water vapor permeability $\left(V_{p}\right)$ was calculated according to Equations5 and 6:

$V_{p}=\frac{T_{v} . l}{P_{\text {vap }} . \Delta R H}($ Equation 5)

$T_{v}=\frac{W_{v}}{t . A}$

(Equation 6)

where $W_{v}$ is the weight of the vapor that permeated through the sample at time $t, A$ is the area of the sample exposed to the atmosphere, $l$ is the thickness of the sample, $P_{\text {vap }}$ is the 
vapor pressure and $\triangle R H$ is the difference between the relative humidity above and below the sample.

\subsubsection{Water contact angle}

Measurements of static contact angle of water were performed with equipment OCA20 (Dataphysics) after compacting the samples with a manual press for about $1 \mathrm{~min}$, to avoid the influence of porosity and surface irregularities. The results were the average of twenty measurements for each sample.

\subsubsection{Simultaneous data thermal analysis (SDT)}

The thermal and calorimetric behavior was determined on a Simultaneous data thermal analysis (SDT) equipment (Q100, TA Instruments, New Castle DE, USA) using standardalumina crucibles, heating at $10^{\circ} \mathrm{C} / \mathrm{min}$ from $25^{\circ} \mathrm{C}$ up to $700{ }^{\circ} \mathrm{C}$ ). The instrument was calibrated with indium. The results are expressed as the average of at least two independent samples.

\section{Results and Discussion}

\subsection{Aspect, morphology and thickness}

The membranes did not show evidence of major changes in color or in integrity after being exposed to the $\mathrm{scCO}_{2}$ in the different conditions when evaluated with the naked eye.The typical morphologiesof the membranes analyzed by SEM are shown in Figure 2.It is possible to notice that the obtained membranes have a porous and lamellar structure, and also that the pores do not cross the entire structureof the matrix. This characteristic favors their application as dressings for the treatment of skin lesions, since 
the penetration of microorganisms into the wound would be hindered[4, 14].

The thickness of a membranealso has great influence on its performance as a biomaterial. The measured thickness values ranged from 0.12 to 0.84 mmdepending on the Pluronic F68 proportion and on the pressure conditions (Table 1).For the treatment of skin lesions, it is recommended that the thickness of the dermis temporary substitute is thinner than the human dermis, which varies from 0.5 to $2 \mathrm{~mm}$, depending on age, sex and body region [15].Therefore, regarding thickness, the membranes obtained in this work can be considered adequate for the treatment of skin injuries before or after $\mathrm{scCO}_{2}$ processing.

Samples prepared in the presence of growing amounts of Pluronic F68 were significantly thicker than those obtained with smaller amounts of surfactant, what can be explained by the greater incorporation of air into the polymeric mixture promoted by the surfactant under mechanical stirring, as also noticed by Buenoet al.[5]. Therefore, the membranes prepared in the presence of higher Pluronic F68 proportions have bigger pores and greater voids between the transversal layers of the membranes, as can be observed in Figure 2.

There wereno significant changes in thickness after $\mathrm{scCO}_{2}$ processing for sample $\mathrm{P} 0 \%$, while the average thickness increased up to $75 \%$ for sample $\mathrm{P} 2 \%$ and $68 \%$ for sample P10\% (Table 1). However, the increase in the average thickness with the increase of pressure observed could not be confirmed by SEM (Figure 2), probably because the analysis was performed with small samples $(1 \mathrm{~cm} \times 1 \mathrm{~cm})$, which only represent a section of the membrane.

The increase in thickness of samples $\mathrm{P} 2 \%$ and $\mathrm{P} 10 \%$ may be related to the presence of Pluronic F68, which, according to Bhomiaet al. [16], melts in the processing conditions employed. The melting of Pluronic F68 would favor the mobility of the polysaccharide 
molecules and facilitate the plasticizing effect by $\mathrm{scCO}_{2}$. Besides, Pluronic F68 decreases interfacial tension between the water present in the membranes and $\mathrm{CO}_{2}$ [17], aiding the diffusion of $\mathrm{CO}_{2}$ in the membranes and their consequent plasticization.

The observed swelling was irreversible, probably because of the limited flexibility and elasticity of the produced material.The employed depressurization rate, which influences the polymers relaxation rate [18], might also have been a cause of the irreversible swelling.

\subsection{Surface area, real density and porosity}

Pore size and structure play an important role in the efficacy of skin scaffolds, which must have high porosity, with large interconnected pores, favoring cellular migration and reorganization, as well as the diffusion of nutrients and the removal of metabolic wastes. Furthermore, porosity regulates important processes for tissue regeneration such as angiogenesis and permits tissue growth and integration with the surrounding healthy tissue [19-21]. Surface area is also relevant because the greater the surface area, the greater the area to provide a suitable environment to which cells could adhere, migrate and grow.

According to Table 1, the real density of the non-processed samples decreased in the order $\mathrm{P} 0 \%>\mathrm{P} 10 \%>\mathrm{P} 2 \%$, as a consequence, the calculated porosity decreased in the order $\mathrm{P} 10 \%>\mathrm{P} 0 \%>\mathrm{P} 2 \%$. The surface area results followed the same tendency observed for real density.

It can be noticed that, despite the fact that membranes prepared with growing amounts of Pluronic F68 have increased pore sizes (as indicated by SEM analysis) and thickness, the measured real density and the calculated porosity did not followed the same tendency for sample P2\%.It can also be noticed that sample P2\% has the smallest 
number ofmicropores, since $\mathrm{N}_{2}$ adsorption analysis is sensitive only pores smaller than $0.1 \mu \mathrm{m}$.

Regarding $\mathrm{scCO}_{2}$ processed samples, it was noticed that real density and porosity tended toincrease after $\mathrm{scCO}_{2}$ processing(Table 1). It is believed that $\mathrm{CO}_{2}$ caused a rearrangement of the polymeric molecules by interacting with some polysaccharides groups, such as $-\mathrm{O}-$ and $-\mathrm{NH}_{2}[22,23]$,inducing the approximation of the polymeric chains. Consequently, the membranes' lamellae became more compact, as indicated by the increase of real density. On the other hand, surface area did not show a clear tendency of variation with pressure (Table 1).

The effect of Pluronic F68 on real density and porosity upon processing with $\mathrm{scCO}_{2}$ is not evident at first. However, when the relative increases of real density and porosity are calculated, it can be noted that sample P2\% presented the highest increase of porosity and sample P10\% presented the highest increase of real density, which shows better plasticization by $\mathrm{scCO}_{2}$ in the presence of Pluronic F68.

According to the literature, skin scaffolds should have porosity greater than $0.9[1,24]$. Therefore, samples $\mathrm{P} 10 \%$ processed at 100 and 300 bar would be more adequate for this use.

\subsection{Hydrophilicity analysis}

The behavior of membranes in the presence of moisture is another important characteristic to be evaluated. In the case of use in skin lesions,biomaterials should be capable of retaining moisture at appropriate levels, since dry dressings may desiccate the wound and too much moisture may result in maceration of the wound bed. Water vapor sorption, permeability and water contact angle results are shown in Figure 3.

Water vapor sorption capacities were measured duringtime, and the values shown in 
Figure 3 represent the maximum values attained after saturation, which occurred around 8 hours. Water vapor sorption increased according to Pluronic F68 proportion, which is in accordance with the increase of thickness and changes in morphology. It was noted that $\mathrm{scCO}_{2}$ processing at 300 bar significantlyincreased water vapor sorption capacity for all samples. The relative increases were $42 \%, 53 \%$, and $41 \%$ for samples $\mathrm{P} 0 \%, \mathrm{P} 2 \%$ and $\mathrm{P} 10 \%$, respectively. On the other hand, processing at 100 bar significantly increased water vapor sorption only for sample $\mathrm{P} 10 \%$, in $37 \%$.

As previously mentioned, $\mathrm{scCO}_{2}$ may have caused irreversible swelling of the polymeric network. Therefore, the processed samples would have more void spaces inside their structure, absorbing more moisture. The increase in water vapor sorption after supercritical processing was considered as a positive result, since it implicates in a better capacity of absorbing wound exudates and improved mass transfer inside the membrane.

In comparison with the literature, water vapor sorption capacities for $\mathrm{N}$ carboxybutylchitosanand agarose wound dressings were of $30 \%$ to $50 \%$. These values were considered adequate for commercial wound dressings [8].Water vapor sorption capacities of wound dressings made of collagen and cellulose, N-carboxybutylchitosan and hyaluronic acid were reported to be $57 \%, 29 \%$ and $36 \%$, respectively, and these values were also considered as convenient [25].

Therefore, according to these authors, water vapor sorption capacities from 29 to $57 \%$ may be considered as suitable. Given thatP2\% samples processed with $\mathrm{scCO}_{2}$ at 300 bar as well as processed and non-processed $\mathrm{P} 10 \%$ samples were able to attain values in this range, these biomaterials may be suitable for the treatment of skin lesions with this regard.

Water vapor permeabilityof the non-processed samples also increased with Pluronic 
F68 proportion due to changes in morphology. The supercritical processing of samples P0\% did not alter their permeability values significantly. However, permeability increased for samples $\mathrm{P} 2 \%$ and $\mathrm{P} 10 \%$ after processing at 100 bar. Further increases in permeability were not observed after processing at 300 bar.

It is recommended that the water vapor transmission ratefor wound dressings is in the range between 300 to $3000 \mathrm{~g} / \mathrm{m}^{2}$.day, depending on the type of injury and on the healing phase[26]. In terms of permeability, it means that the obtained membranes should

present values between 0.18 to $12.4 \mathrm{x} 10^{-14} \mathrm{~kg} \cdot \mathrm{s}^{-1} \cdot \mathrm{m}^{-1} \cdot \mathrm{Pa}^{-1}$. Therefore, it can be concluded that the membranes would be more adequate for the treatment of wounds producing low amounts of exudate.

The measured water contact angles indicate that the membranes are hydrophilic, since values lower than $90^{\circ}$ [27]were attained. The obtained results did not show a tendency of variation according to the Pluronic F68 proportion or $\mathrm{scCO}_{2}$ pressure.

\subsection{Simultaneous data thermal analysis (SDT)}

The thermal behavior of the isolated polymers and the membranes were analyzed by thermal gravimetric analysis (TGA) and differential scanning calorimetry (DSC). The results obtained are shown in Figure4. The main events observed in the thermal gravimetric analysis (TGA) are summarized in Table 2.

The TGA analysis of chitosan and alginate showed two thermal events. The first one, attributed to water loss,occurred at temperatures lower than $100^{\circ} \mathrm{C}$. The subsequent thermal events were associated to the degradation of the polymers.

In the analysis of chitosan, a mass loss of $44 \%$ was verified in the second thermal event, with a peak at $300^{\circ} \mathrm{C}$. Similar data were found by Martins et al.[28], who observed a degradation peak at $312^{\circ} \mathrm{C}$ with a mass loss of $59.8 \%$. This degradation step can be 
attributed to depolymerization and pyrolytic decomposition of the polysaccharide[29]. A mass loss of $33 \%$ wasdetectedfor the thermal degradation of alginate in the second event, with a peak at $244^{\circ} \mathrm{C}$. The literature shows similar results regarding the degradation of alginate, with a peak at $226^{\circ} \mathrm{C}$ and a mass loss of $40 \%$, which is attributed to the formation of $\mathrm{Na}_{2} \mathrm{CO}_{3}$ and carbonized material [30].

Differently from chitosan and alginate, Pluronic F68 had a single thermal event, with a degradation peak at $390^{\circ} \mathrm{C}$, and a mass loss of $96 \%$. Wu et al.[31]also observed that Pluronic F68 degraded in a single step, but at a lower temperature, of $320^{\circ} \mathrm{C}$.

In the TGA analysis of the non-processed membranes, the first thermal event, which can be attributed to water loss, occurred at peak temperatures varying from 51 to $60^{\circ} \mathrm{C}$, with mass losses varying from 12 to $21 \%$. The more porous membranes had higher water losses, what may be explained by their highest water vapor sorption. The main degradation peaks of samples $\mathrm{P} 2 \%$ and $\mathrm{P} 10 \%$ occurred at 234 and $232^{\circ} \mathrm{C}$, respectively, which are temperatures lower than the degradation temperature of pure alginate $\left(244^{\circ} \mathrm{C}\right)$. On the other hand, sample $\mathrm{P} 0 \%$ had a degradation peak at $275^{\circ} \mathrm{C}$, which is a temperature lower than the degradation temperature of pure chitosan. A shoulder around $230^{\circ} \mathrm{C}$ was also observed, which is a temperature lower than the degradation temperature of pure alginate. The different thermogravimetric behaviors between nonprocessed samples can be due to the presence of Pluronic F68, which may alter the interactions involved in the formation of the polyelectrolyte complex (PEC).

The presence of a single degradation step may be considered as an indicative of the presence of a PEC according to Smithaet al.[32], who observed that the chitosanalginate complex had a degradation peak at $260^{\circ} \mathrm{C}$. Anbinderet al.[33] also observed that alginate capsules covered with chitosan and crosslinked with calcium ions had a degradation peak at $250^{\circ} \mathrm{C}$, with mass loss of $40 \%$. Therefore, it can be inferred that the 
formation of a chitosan and alginate PEC is favored in the presence of Pluronic F68.

Sample P10\% exhibited also a small degradation peak at $393^{\circ} \mathrm{C}$, which could indicate that the surfactant remains in the structure of the membranes even after successive washing steps. However, the residual presence of Pluronic F68 does not negatively affect the biocompatibility as detected by incubation of the material with L929 fibroblasts [5].

TGA analysis of $\mathrm{scCO}_{2}$ processed membranes indicated significant changes in the behavior of sample $\mathrm{P} 0 \%$, which had its main degradation peak narrowed and shifted to a lower temperature. In addition, the shoulder at $230^{\circ} \mathrm{C}$ disappeared. These results may indicate that the PEC became more stable, since the presence of only one degradation peak is an indicative of PEC formation. On the other hand, the behaviors of samples $\mathrm{P} 2 \%$ and $\mathrm{P} 10 \%$ were not altered. It is believed that, since Pluronic F68 favors the formation of PEC, the chitosan-alginate interactions were already strong enough in these samples before $\mathrm{scCO}_{2}$ processing.

The DSC analysis of chitosan and alginateindependently showed two thermal events, as observed in the TGA analysis. The endothermic peaks at 75 and $79^{\circ} \mathrm{C}$ can be attributed to the vaporization of adsorbed water, corroborating the TGA curves. The exothermic peaks observed for these polymers also corroborate to the TGA curves and the literature[33]. Alginate had a degradation peak at $247^{\circ} \mathrm{C}$ and chitosan had a degradation peak at $310^{\circ} \mathrm{C}$.

Pluronic F68 had two endothermic peaks in the DSC analysis, one at $56^{\circ} \mathrm{C}$ and other at $395^{\circ} \mathrm{C}$. The first one is due to melting, according to similar data obtained by Verger et al.[34]. The second one can be related to oxidation or decomposition, since a degradation peak at $390^{\circ} \mathrm{C}$ was observed in the thermal gravimetric analysis.

In the DSC analysis of the non-processed membranes, the first endothermic peak was 
attributed to water loss. Sample P0\% had two exothermic peaks, at 217 and $290^{\circ} \mathrm{C}$. On the other hand, samples $\mathrm{P} 2 \%$ and $\mathrm{P} 10 \%$ had only one exothermic peak, at 236 and $233^{\circ} \mathrm{C}$, respectively.

It is believed that, in the analysis of sample $\mathrm{P} 0 \%$, the characteristic peaks of pure chitosan and alginate were shifted in $-20^{\circ} \mathrm{C}$ and $-30^{\circ} \mathrm{C}$, respectively. On the other hand, samples $\mathrm{P} 2 \%$ and $\mathrm{P} 10 \%$ had only one degradation peak, at a temperature near the characteristic peak of pure alginate. According to Anbinderet al.[33], the shifting of the characteristic temperature of alginate could indicate the presence of a PEC. Unlike the TGA analysis, the peak related to Pluronic F68 could not be detected by DSC in samples P10\%.

The DSC analysis of the processed samples indicated that only sample P0\% was modified by $\mathrm{scCO}_{2}$, changing from two to only one exothermic peak at a temperature lower than the characteristic peak temperature of alginate, which indicates the increase in chitosan-alginate interactions, as observed in the TGA analysis.

\section{Conclusions}

Chitosan-alginate membranes prepared in the absence or presence of different Pluronic F68 proportions, processed or not with $\mathrm{scCO}_{2}$ at $45^{\circ} \mathrm{C}$ and 100 or 300 bar for 2 hours,presented adequate characteristics for the treatment of skin injuries with low amounts of exudate.

ByincreasingPluronic F68 proportions, biomaterials with higher thickness, water vapor sorption and permeability were obtained.The presence of this surfactant during membrane preparation also resulted in improvements of chitosan-alginate interactions and facilitated the plasticization of the material by $\mathrm{scCO}_{2}$. Supercritical $\mathrm{CO}_{2}$ processing 
caused the same effects as Pluronic F68, besides increasing the biomaterials porosity. Therefore, it is believed that $\mathrm{scCO}_{2}$ and Pluronic F68 may play a similar role regarding structuring the chitosan-alginate PEC.

$\mathrm{ScCO}_{2}$ processing of membranes prepared with Pluronic $\mathrm{F} 68$ resulted in materials with better prospects for use as wound dressings. Particularly, sample P10\% processed with $\mathrm{scCO}_{2}$ in both conditions employed would be also adequate for use as a skin scaffold in tissue engineering.

Therefore, the obtained results indicate high potential ofsupercritical technologies forprocessingchitosan-alginate PEC membranes, aiming at changes of their physicochemical properties or even forthe impregnation of bioactive compounds.

\section{Acknowledgements}

The authors thank the grant sponsors: Fundação de Amparo à Pesquisa do Estado de São Paulo (FAPESP), Coordenação de Aperfeiçoamento de Pessoal de Nível Superior (CAPES) and Conselho Nacional de Desenvolvimento Científico e Tecnológico (CNPq), from Brazil, Fundação para a Ciência e a Tecnologia (FCT) from Portugal and the Programa Iberoamericano de Ciencia y Tecnologia para el Desarrollo (CYTED).

\section{References}

1. F. Khan, S.R. Ahmad, Polysaccharides and their derivatives for versatile tissue engineering application, Macromolecular Bioscience 13 (2013) 395-421.

2. Y.Luo,Q.Wang, Recent development of chitosan-based polyelectrolyte complexes with natural polysaccharides for drug delivery, International Journal of Biological Macromolecules64 (2014)353-367. 
3. G.D.Mogoşanu, A.M. Grumezescu, Natural and synthetic polymers for wounds and burns dressing, International Journal of Pharmaceutics 463 (2014) 127-136.

4. C.Z. Bueno, A.M. Moraes, Development of porous lamellar chitosan-alginate membranes: Effect of different surfactants on biomaterial properties, Journal of Applied Polymer Science 122 (2011) 624-631.

5. C.Z. Bueno, A.M.A. Dias, H.J.C. Sousa, M.E.M. Braga, A.M. Moraes, Control of the properties of porous chitosan-alginate membranes through the addition of different proportions of Pluronic F68, Materials Science and Engineering C 44 (2014) 117-125.

6. G. T. Rodeheaver, L. Kurtz, B. J. Kircher, R. F. Edlich, Pluronic F68: A promising new skin wound cleanser, Annals of Emergency Medicine9 (1980) 572-576.

7. M.E.M. Braga, M.T.V. Pato, H.S.R.C. Silva, E.I. Ferreira, M.H. Gil, C.M.M. Duarte, H.C. De Sousa, Supercritical solvent impregnation of ophthalmic drugs on chitosan derivatives, Journal of Supercritical Fluids 44 (2008) 245-257.

8. A.M.A. Dias, M.E.M. Braga, I.J. Seabra, P. Ferreira, M.H. Gil, H.C. De Sousa, Development of natural-based wound dressings impregnated with bioactive compounds and using supercritical carbon dioxide, International Journal of Pharmaceutics 408 (2011) 9-19.

9. A.M.A. Dias, M.E.M. Braga, I.J. Seabra, H.C. De Sousa, Supercritical solvent impregnation of natural bioactive compounds in $\mathrm{N}$-Carboxybutylchitosan and agarose membranes for the development of topical wound healing applications, Technologies for Medical SciencesLecture Notes in Computational Vision and Biomechanics1 (2012) 243-266.

10. A.P. Rodrigues, Preparation and characterization of chitosan and alginate membranes designed for the therapy of lesions, Doctoral dissertation, State 
University of Campinas, School of Chemical Engineering (2008).

11. J. W. Rhim, Physical and mechanical properties of water resistant sodium alginate films,Lebensmittel-Wissenschaft\&Technologie 37 (2004) 323-330.

12. M. A.Moraes,M. M. Beppu, Biocomposite membranes of sodium alginate and silk fibroin fibers for biomedical applications, Journal of Applied Polymer Science130 (2013) 3451-3457.

13. ASTM. Standard test methods of water vapor transmission of material. Annual Book of ASTM Standards, American Society for Testing and Materials, Philadelphia, E 96-95, 1995.

14. W.L.J. Hinrichs, E.J.C.M.P. Lommen, R.H. Wildevuur, J. Feijen, Fabrication and characterization of an asymmetric polyurethane membrane for use as a wound dressing, Journal of Applied Biomaterials 3 (1992) 287-303.

15. J. Ma, H. Wang, B. He, J. Chen, A preliminary in vitro study on the fabrication and tissue engineering applications of a novel chitosan bilayer material as a scaffold of humamneofetal dermal fibroblasts, Biomaterials 22 (2001) 331-336.

16. R. Bhomia, V. Trivedi, J.C. Mitchell, N.J. Coleman, M.J. Snowden. Effect of pressure on the melting point of Pluronics in pressurized carbon dioxide. Industrial \& Engineering Chemistry Research 53 (2014) 10820-10825.

17. H.M. Woods, M.M.C.G. Silva, C. Nouvel, K.M. Shakesheff, S.M. Howdle, Materials processing in supercritical carbon dioxide: surfactants, polymers and biomaterials. Journal of Materials Chemistry 14 (2004) 1663-1678.

18. D.L. Tomasko, H. Li, D. Liu, X. Han, M.J. Wingert, L.J. Lee, K.W. Koelling, Review of $\mathrm{CO}_{2}$ applications in the processing of polymers, Industrial \& Engineering Chemistry Research 42 (2003)6431-6456.

19. E. Reverchon, S.Cardea, Supercritical fluids in 3-D tissue engineering, Journal of 
Supercritical Fluids 69 (2012) 97- 107.

20. C. Ji, N. Annabi, A. Khademhosseini, F. Dehghani, Fabrication of porous chitosan scaffolds for soft tissue engineering using dense gas $\mathrm{CO}_{2}$, ActaBiomaterialia 7 (2011) 1653-1664.

21. W. Zhao, X. Jin, Y. Cong, Y. Liu, J. Fu, Degradable natural polymer hydrogels for articular cartilage tissue engineering, Journal of Chemical Technology and Biotechnology 88 (2013) 327-339.

22. S. Kumar, J.A. Silva, M.Y. Wani, C.M.F. Dias, A.J.F.N. Sobral, Studies of carbondioxide capture on porous chitosanderivative, Journal of Dispersion Science and Technology(2015) DOI: 10.1080/01932691.2015.1035388.

23. O.R. Davies, A.L. Lewis, M.J. Whitaker, H. Tai, K.M. Shakesheff, S.M. Howdle, Applications of supercritical $\mathrm{CO}_{2}$ in the fabrication of polymer systems for drug delivery and tissue engineering, Advanced Drug Delivery Reviews 60 (2008) 373387.

24. N. S.Greaves,S. A.Iqbal,M.Baguneid, A. Bayat, The role of skinsubstitutes in the management of chronic cutaneous wounds, Wound Repair and Regeneration 21 (2013) 194-210.

25. A.M.A. Dias, A. Rey-Rico, R.A. Oliveira, S. Marceneiro, C. Alvarez-Lorenzo, A. Concheiro, R.N.C. Junior, M.E.M. Braga, H.C. De Sousa, Wound dressings loaded with an anti-inflammatory juca (Libidibiaferrea) extract using supercritical carbon dioxide technology, Journal of Supercritical Fluids 74 (2013) 34-45.

26. C.B. Shah, R.F. Vitaris, E.D. Fink, S. Orr, B. Dowd, A. Tranchemontagne, K. Ward, H. Swaniker, H.A. Patel, Antimicrobial foam compositions, articles and methods. United States Patent Application Publication US2010/0260824 A1, 2010.

27. R. Förch, H. Schönherr, T. A. Jenkins, Surface design: Applications inbioscience 
and nanotechnology. $1^{\text {st }}$ ed. Wiley-VCH, Weinheim, 2009.

28. A.F. Martins, A.G.B. Pereira, A.R. Fajardo, A.F. Rubira, E.C. Muniz, Characterization of polyelectrolytes complexes based on N,N,N-trimethyl chitosan/heparin prepared at different $\mathrm{pH}$ conditions, Carbohydrate Polymers 86 (2011) 1266-1272.

29. J.T. Martins, M.A. Cerqueira, A.A. Vicente, Influence of a-tocopherol on physicochemical properties of chitosan-based films, Food Hydrocolloids 27 (2012) 220-227.

30. M.I. Popa, G. Lisa, N. Aelenei, Thermogravimetric characterization of chitosan/alginate microparticles loaded with different drugs, Polymer Bulletin 61 (2008) 481-490.

31. Y. Wu, F.B. Che, J.H. Chen, Synthesis and characterization of a amphiphilicPluronic-poly(D,L-lactide-co-glycolide) copolymer and their nanoparticles as protein delivery systems, Journal of Applied Polymer Science 110 (2008) 1118-1128.

32. B. Smitha, S. Sridhar, A.A. Khan, Chitosan-sodium alginate polyion complexes as fuel cell membranes, European Polymer Journal 41 (2005) 1859-1866.

33. P.S.Anbinder,L.Deladino,A.S.Navarro,J.I.Amalvy,M.N. Martino, Yerba mate extract encapsulation with alginate and chitosan systems: interactions between active compound encapsulation polymers, Journal of Encapsulation and Adsorption Sciences 1 (2011) 80-87.

34. M. L. L. Verger, L. Fluckiger, Y. I. Kim, M. Hoffman, P. Maincent, Preparation and characterization of nanoparticles containing an antihypertensive agent, European Journal of Pharmaceutics and Biopharmaceutics 46 (1998) 137-143.

\section{Figure Captions}


Figure 1. High pressure cell with $\mathrm{scCO}_{2}$ containing $1 \mathrm{~cm} \times 1 \mathrm{~cm}$ membrane samples in stainless steel supports.

Figure 2. Scanning electron microscopy (SEM) of the prepared samples in the presence of different Pluronic F68 proportions, before and after supercritical $\mathrm{CO}_{2}$ processing at 100 or 300 bar for two hours at $45^{\circ} \mathrm{C}$ (images magnifications was $150 \times$, and for details $1500 \times)$.

Figure 3. Water vapor sorption (A), permeability (B) and water contact angles (C) of the prepared samples in the presence of different Pluronic F68 proportions, before and after supercritical $\mathrm{CO}_{2}$ processing at 100 or 300 bar for two hours at $45^{\circ} \mathrm{C}$ and different pressures. Samples: P0\% (口), P2\% ( $\square)$ and P10\% ( $\square)$.

Figure 4. TGA and DSC analysis of the porous chitosan-alginate membranes prepared in the presence of different Pluronic F68 proportions, before and after supercritical $\mathrm{CO}_{2}$ processing and pure chitosan, alginate, Pluronic F68: A-D thermal gravimetric analysis and its derivative and $\mathbf{E}-\mathbf{H}$ calorimetric analysis. 
Table 1. Physical properties of chitosan-alginate based samples before and after supercritical $\mathrm{CO}_{2}$ processing at 100 or 300 bar for two hours at $45^{\circ} \mathrm{C}$.

\begin{tabular}{|c|c|c|c|c|c|}
\hline Samples & $\begin{array}{l}\text { Process } \\
\text { conditions }\end{array}$ & Thickness, mm & $\begin{array}{c}\text { Real density, } \\
\mathrm{g} / \mathrm{cm}^{3}\end{array}$ & Porosity & $\begin{array}{c}\text { Surface area, } \mathrm{m}^{2} / \mathrm{g} \\
\text { BET Method }\end{array}$ \\
\hline \multirow{3}{*}{$\mathrm{P} 0 \%$} & Non processed & $0.12 \pm 0.02^{a}$ & $0.947 \pm 0.013^{\mathrm{cd}} *$ & $0.546 \pm 0.009^{\mathrm{bcd}}$ & $5.63^{\mathrm{e}} *$ \\
\hline & $45^{\circ} \mathrm{C}, 100 \mathrm{bar}$ & $0.12 \pm 0.02^{\mathrm{a}}$ & $1.302 \pm 0.039^{f}$ & $0.603 \pm 0.030^{\mathrm{bd}}$ & $6.0 \pm 0.1^{\mathrm{e}}$ \\
\hline & $45^{\circ} \mathrm{C}, 300$ bar & $0.13 \pm 0.01^{\mathrm{a}}$ & $1.366 \pm 0.076^{\mathrm{f}}$ & $0.737 \pm 0.020^{\mathrm{e}}$ & $3.4 \pm 0.2^{\mathrm{d}}$ \\
\hline \multirow{3}{*}{$\mathrm{P} 2 \%$} & Non processed & $0.36 \pm 0.03^{b c}$ & $0.252 \pm 0.002^{a} *$ & $0.227 \pm 0.011^{\mathrm{a}}$ & $1.04^{a b_{*}}$ \\
\hline & $45^{\circ} \mathrm{C}, 100 \mathrm{bar}$ & $0.63 \pm 0.02^{\mathrm{cde}}$ & $0.230 \pm 0.002^{\mathrm{a}}$ & $0.485 \pm 0.020^{b c}$ & $2.2 \pm 0.1^{\mathrm{ac}}$ \\
\hline & $45^{\circ} \mathrm{C}, 300 \mathrm{bar}$ & $0.59 \pm 0.02^{\mathrm{cde}}$ & $0.287 \pm 0.004^{\mathrm{a}}$ & $0.605 \pm 0.012^{\mathrm{bd}}$ & $1.7 \pm 0.1^{\mathrm{abc}}$ \\
\hline \multirow{3}{*}{$\mathrm{P} 10 \%$} & Non processed & $0.50 \pm 0.04^{\text {bcd }}$ & $0.573 \pm 0.003^{b} *$ & $0.727 \pm 0.004^{\mathrm{e}}$ & $7.67^{\mathrm{f}_{*}}$ \\
\hline & $45^{\circ} \mathrm{C}, 100 \mathrm{bar}$ & $0.71 \pm 0.10^{\text {def }}$ & $1.031 \pm 0.029^{\mathrm{cde}}$ & $0.900 \pm 0.004^{\mathrm{f}}$ & $2.0 \pm 0.2^{\mathrm{abc}}$ \\
\hline & $45^{\circ} \mathrm{C}, 300$ bar & $0.84 \pm 0.06^{\text {ef }}$ & $1.146 \pm 0.033^{\mathrm{de}}$ & $0.914 \pm 0.002^{\mathrm{f}}$ & $4.1 \pm 0.2^{d}$ \\
\hline
\end{tabular}

Different letters in the same column indicate significant difference at 95\% confidence limits (Tukey test). *Reference Bueno et al. 2014. 
Table 2. Thermal events observed in the thermal gravimetric analysis of chitosan, alginate, Pluronic F68 and the chitosan-alginate samples before and after supercritical $\mathrm{CO}_{2}$ processing at 100 or 300 bar for two hours at $45^{\circ} \mathrm{C}$.

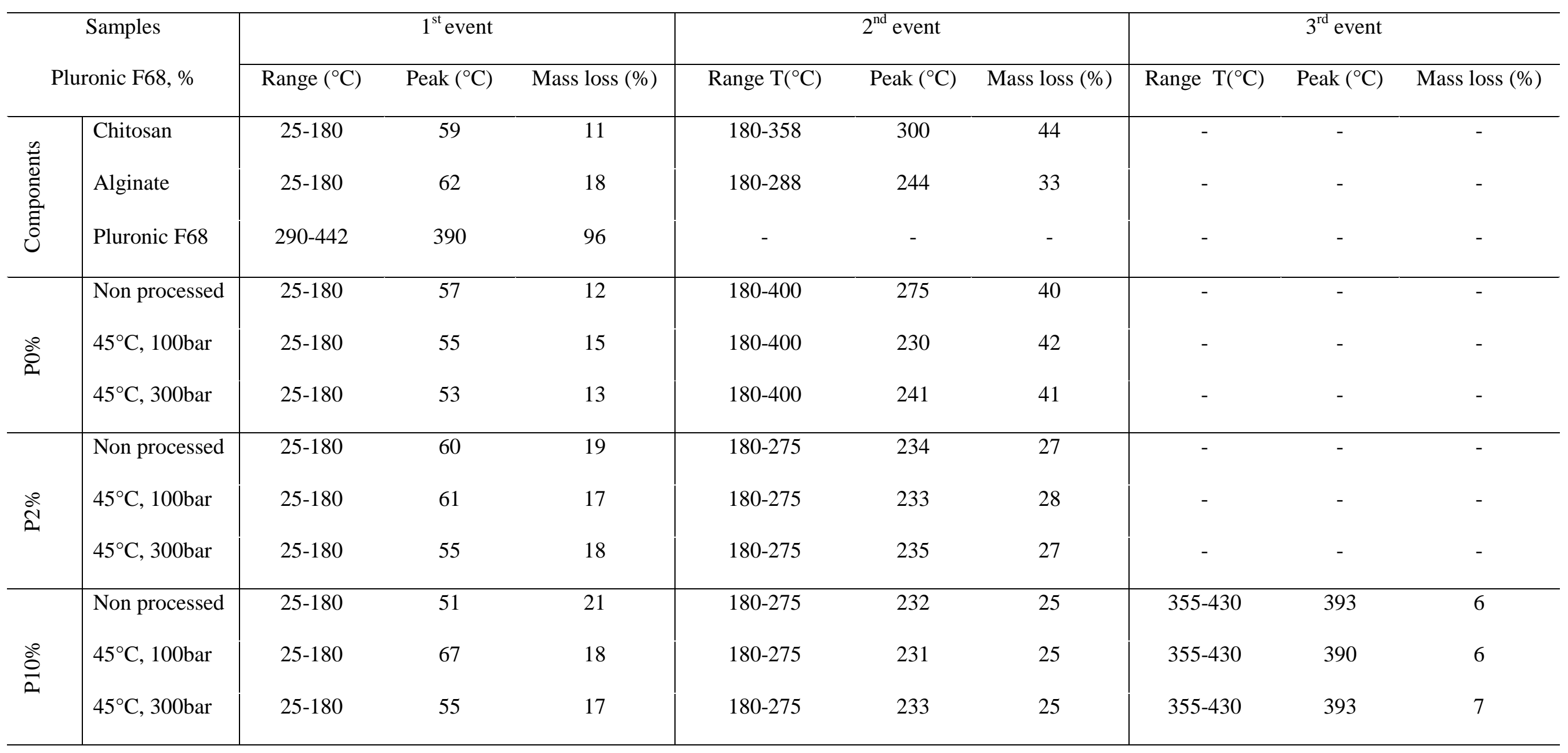


FIG1

$\begin{array}{lll}\mathrm{CO}_{2} & \mathrm{CO}_{2}\end{array}$

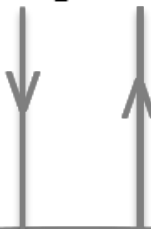

$\mathrm{CO}_{2}$

\section{Samples}

\section{Samples}




\section{P0\%-Non processed}
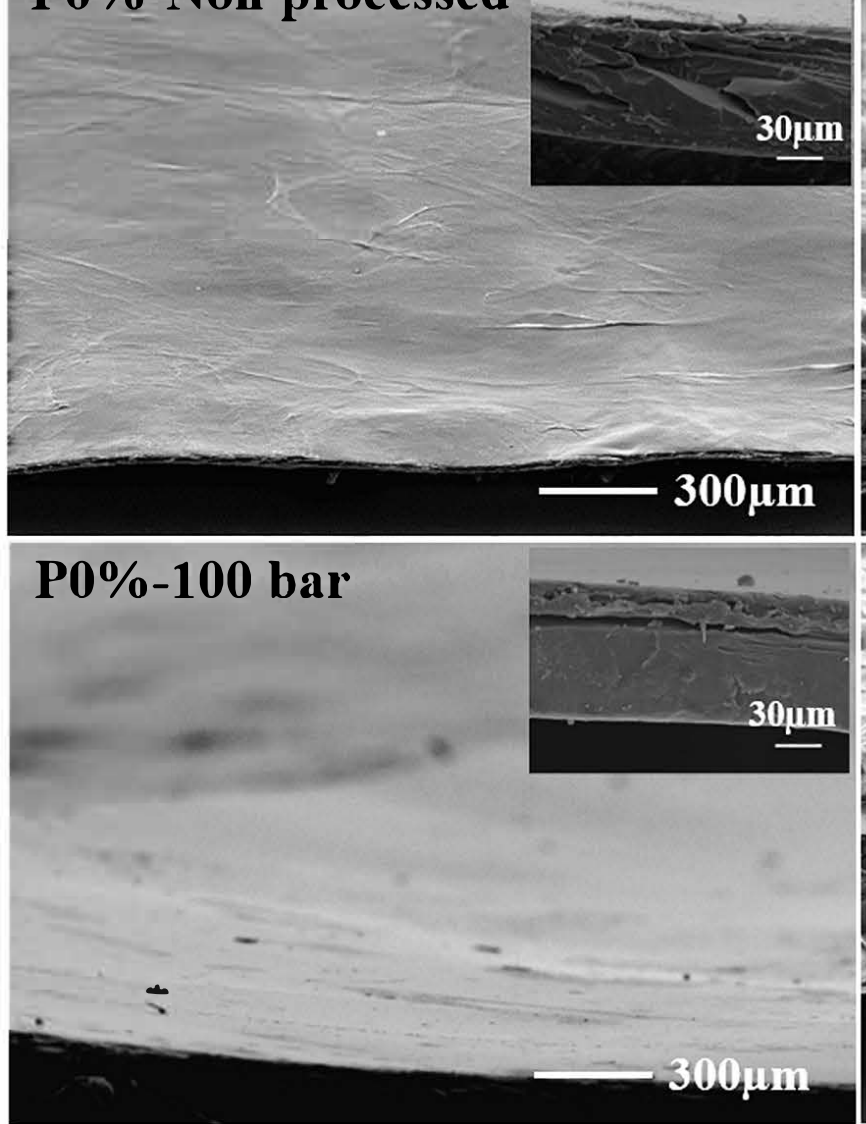

P0\%-300 bar

FIG 2

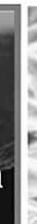

P2\%- Non processed

P10\%-Non processed
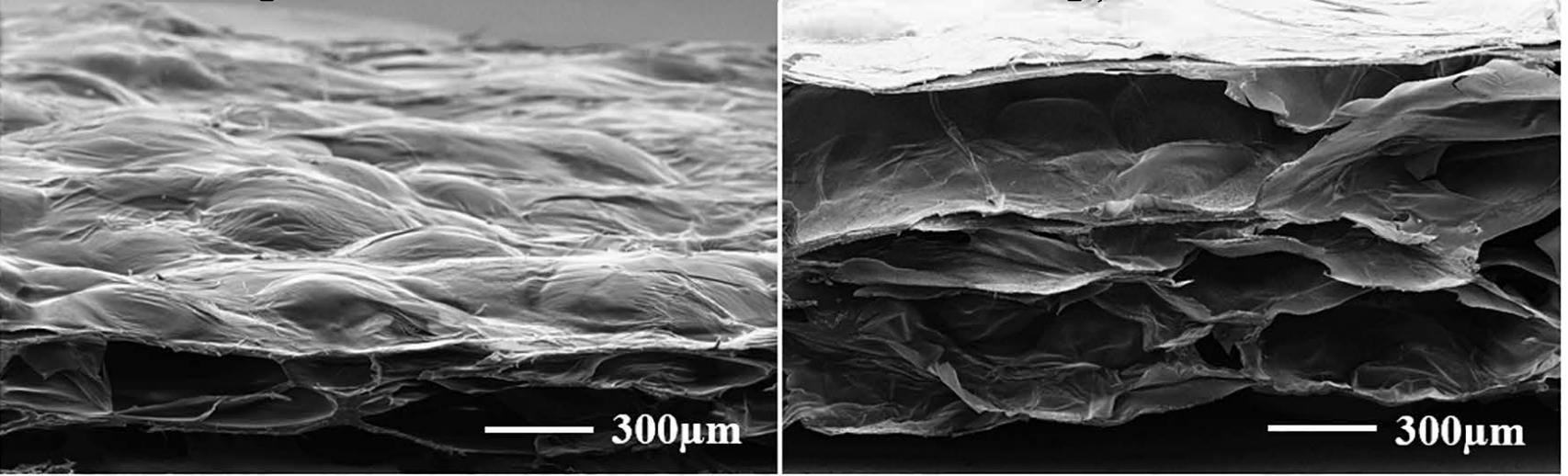

P2\%-100 bar
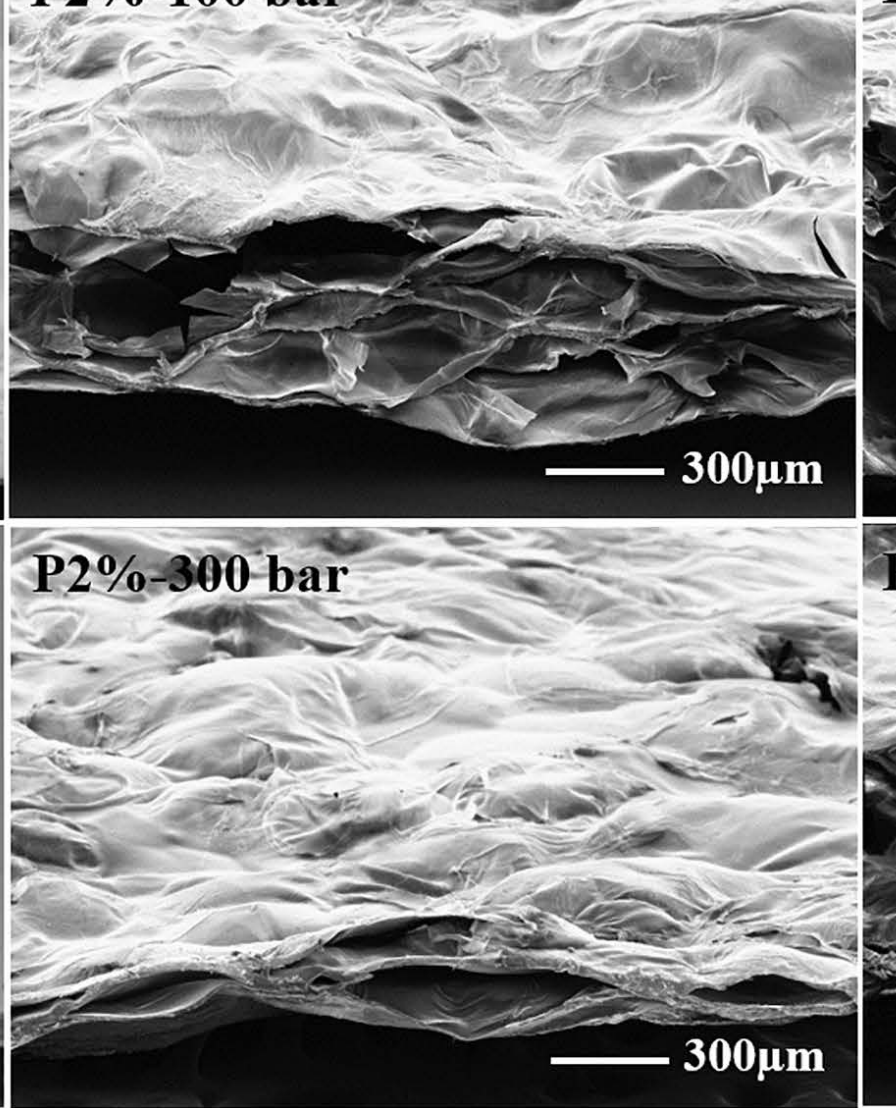

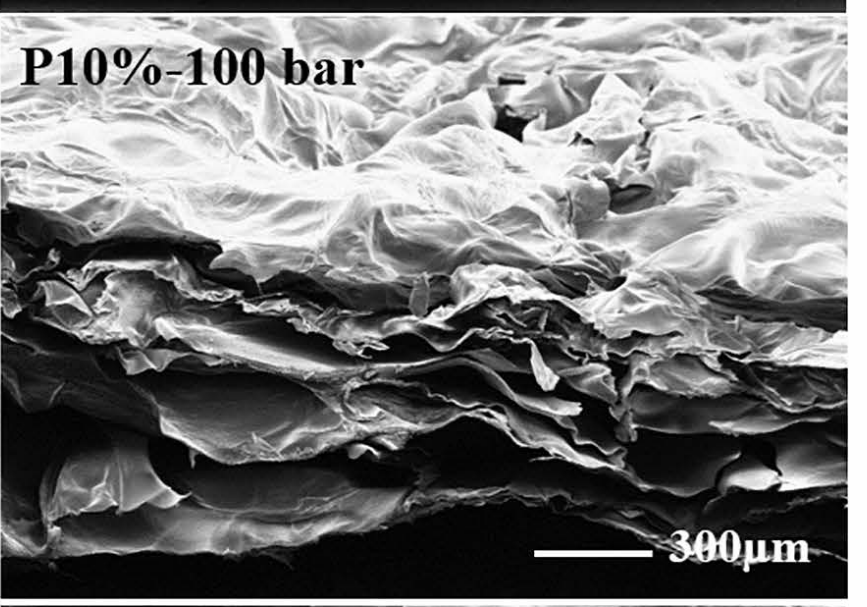

T10\%-300

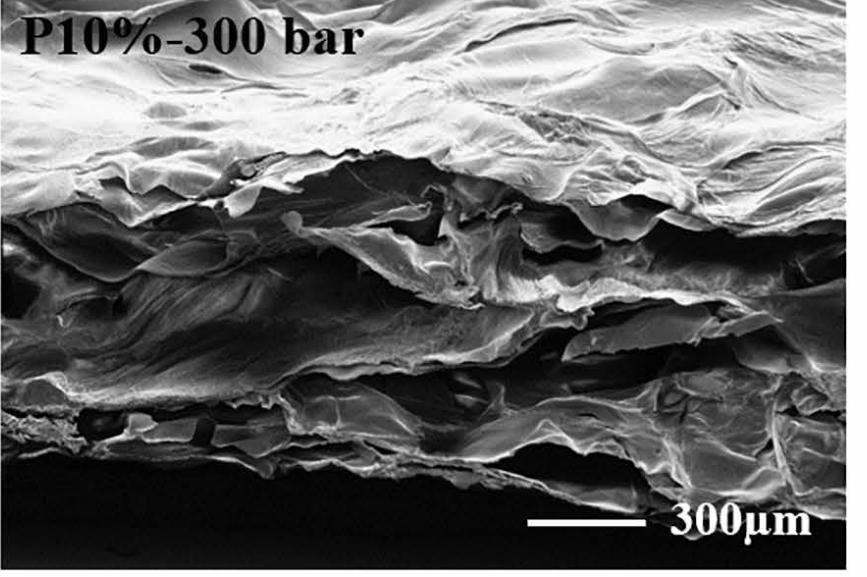




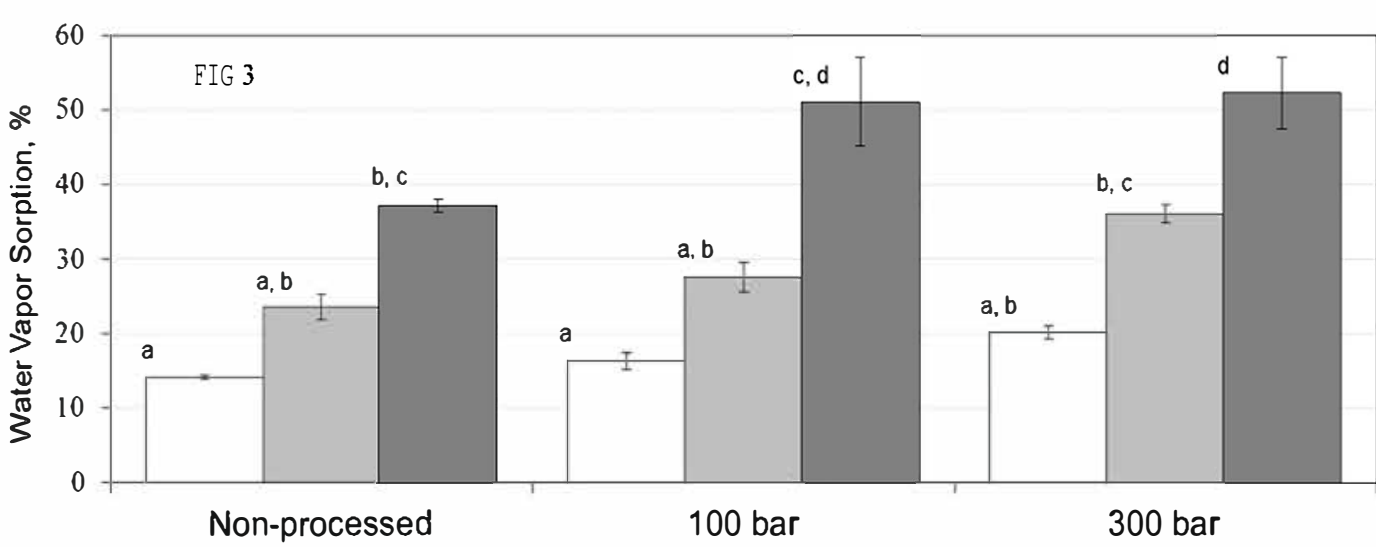

A
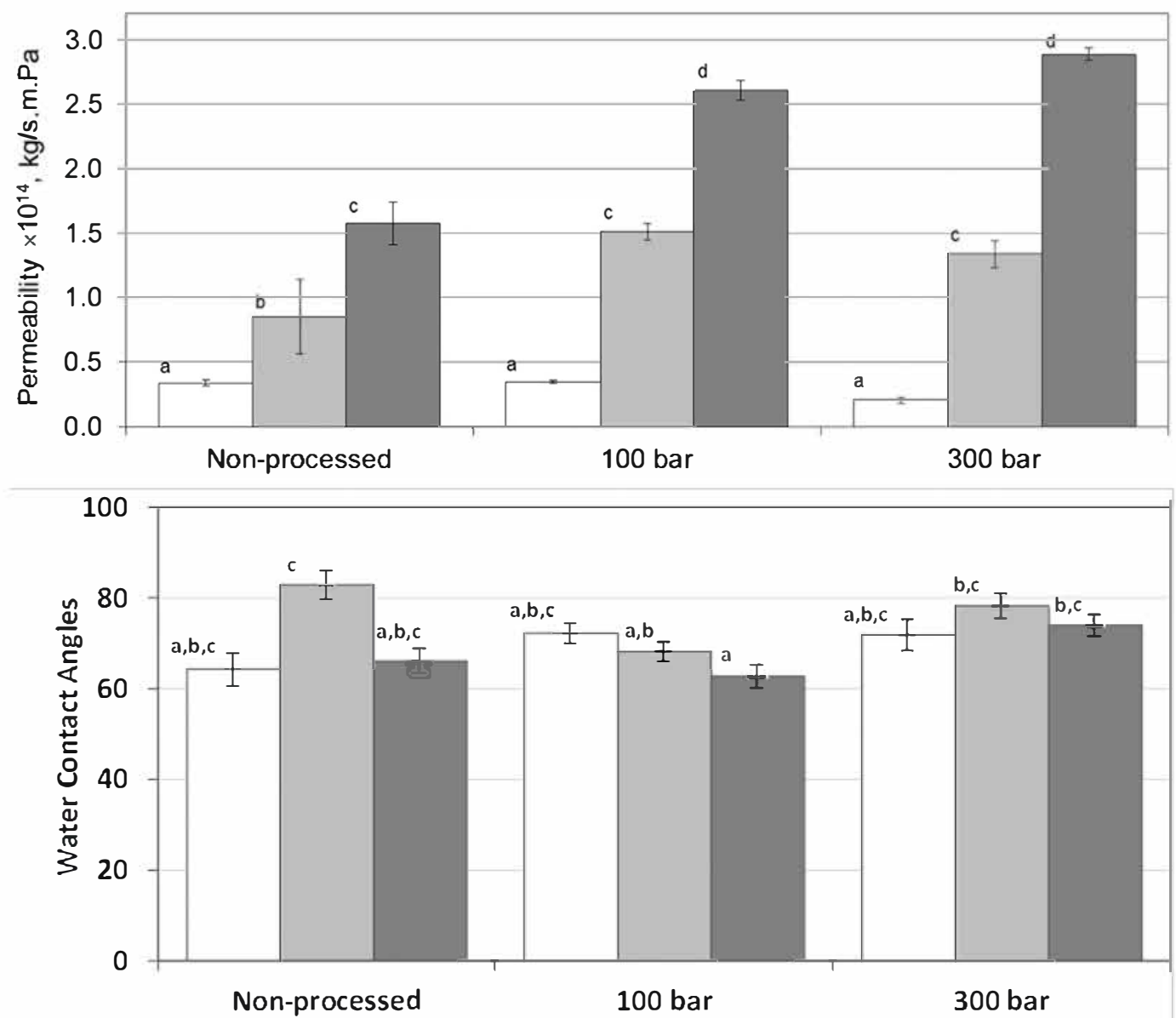


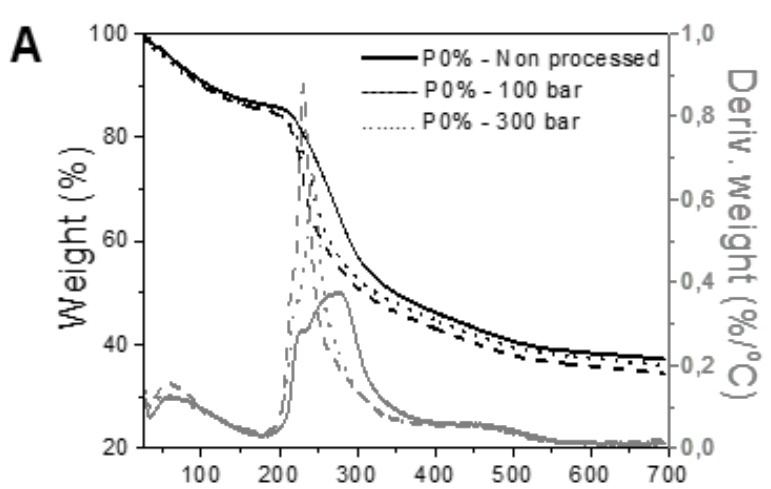

B

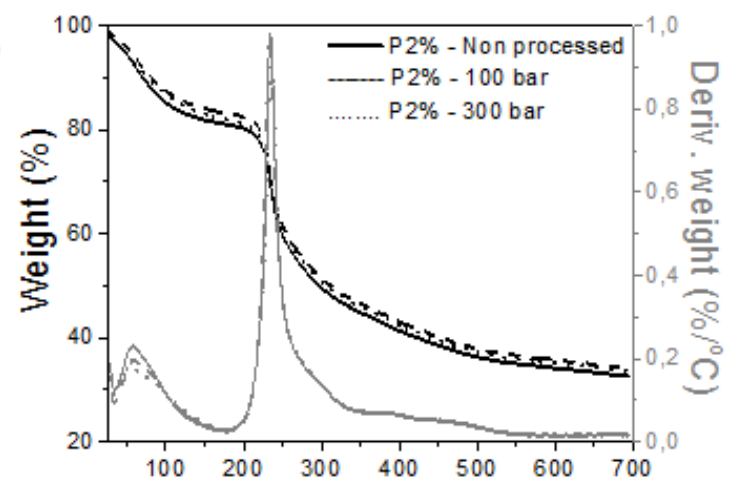

C

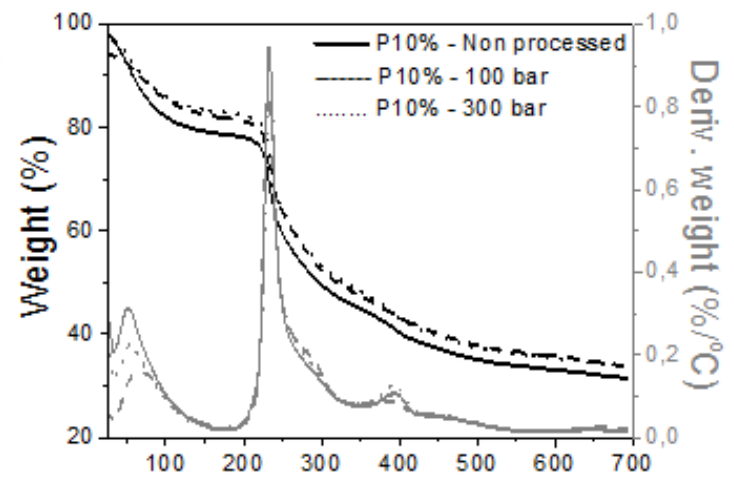

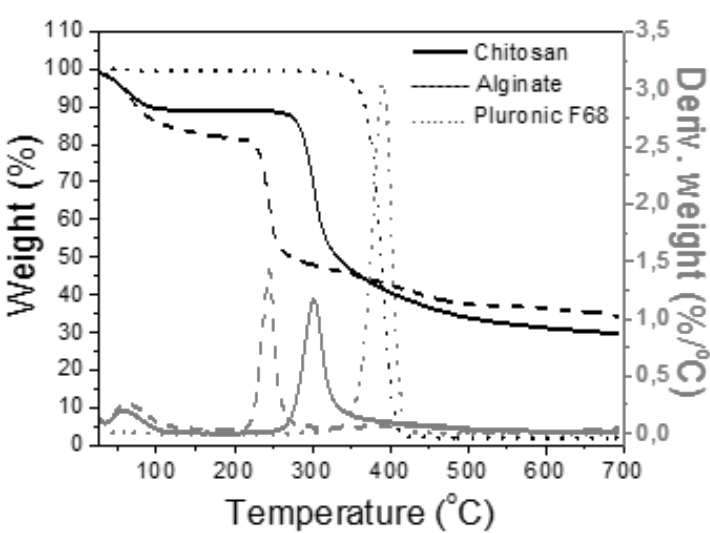

E

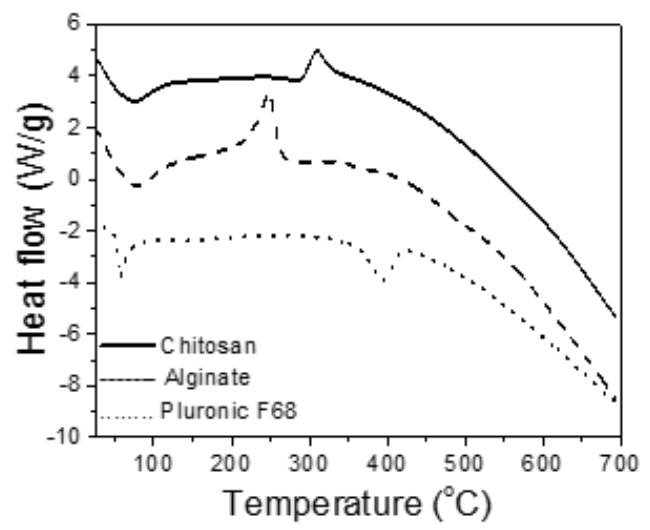

FIG 4

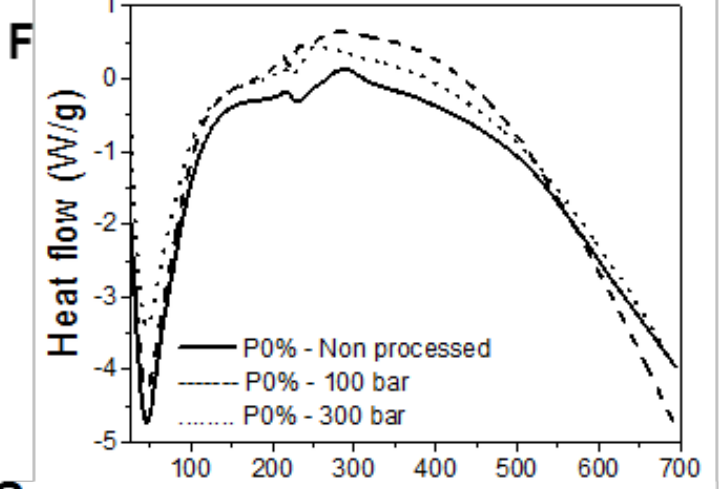

G

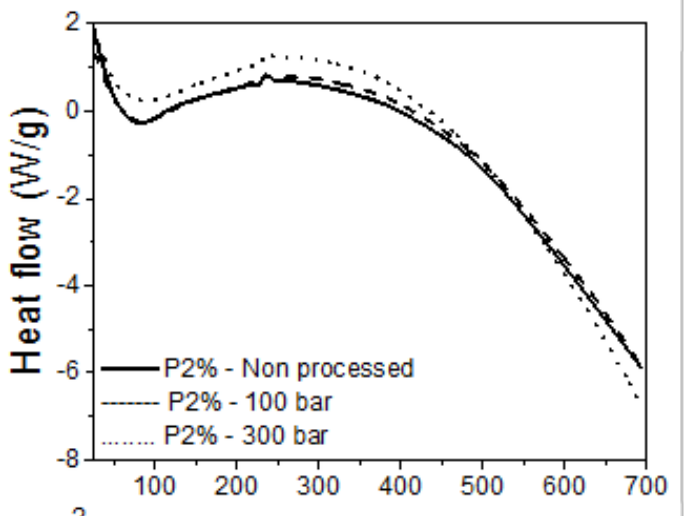

$\mathrm{H}$

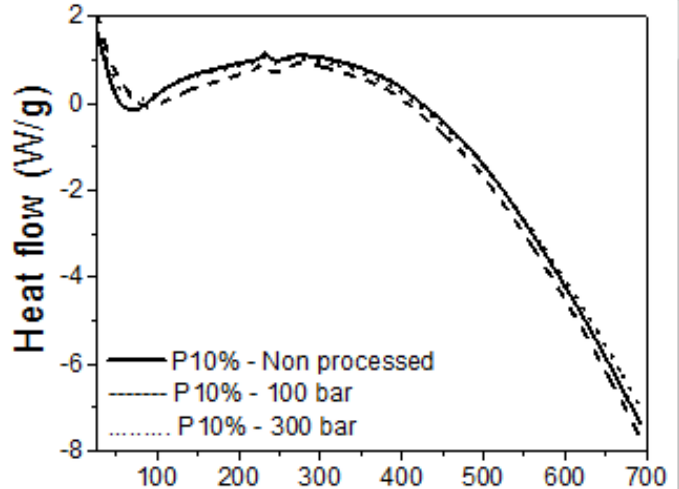

